\title{
Redox-active electrolyte for carbon nanotube-based electric double layer capacitors
}

\author{
Silvia Roldán*, Z. González, Clara Blanco, Marcos Granda, Rosa Menéndez, and \\ Ricardo Santamaría \\ Instituto Nacional del Carbón, CSIC, P.V. Box 73, 33080-Oviedo, Spain
}

\begin{abstract}
.-
The specific capacitance of the MWCNTs was improved by the addition of an electrochemically active compound (Indigo carmine) to an electrolyte generally used in electric double layer capacitors. The pseudocapacitive contribution of the IC trebled the specific capacitance values of the MWCNTs at low current densities (from $17 \mathrm{Fg}^{-1}$ to 50 $\left.\mathrm{Fg}^{-1}\right)$. The good resistance obtained for the MWCNT-based capacitor was not modified with the use of this novel redox-active electrolyte. A reversible process associated to the redox reaction of IC was found to be responsible for the capacitance increase observed. Therefore, a combined effect of double layer formation and pseudocapacitive phenomena is presented. Long-term cycling experiments performed showed good stability with a reduction of the initial capacitance values of $30 \%$ after 10,000 galvanostatic cycles at $360 \mathrm{mAg}^{-1}$. The efficiency of the cell was close to $100 \%$ throughout the experiment.
\end{abstract}

Key words: nanotubes, cyclic voltammetry, indigo carmine, supercapacitor, pseudocapacitance. 


\section{1.- INTRODUCTION}

Electric double layer capacitors (EDLCs) are energy storage devices able to fill the gap existing between batteries and dielectric capacitors from the energy and power density point of view. As compared to batteries, they have much lower energy density, higher power and longer cycle life; as compared to capacitors, they store higher energy but deliver lower power. Carbon materials have been widely studied for this application. In particular, a great attention has been focused on multiwalled carbon nanotubes (MWCNTs) as electrode materials for EDLC, due to their interesting properties such as mechanical and chemical stability, narrow distribution size, high electronic conductivity, low mass density and high ability for the accumulation of charges due to their mesoporous character [1-7]. The presence of mesopores in MWCNTs avoids the diffusion barriers existing in highly microporous activated carbons, where many micropores are not accesible by ions. Thus, the charge transport in the electrical double layer formed in the MWCNT-based electrode/electrolyte interface is favoured during the charge/discharge processes [8]. However, the specific surface area and the specific capacitance of the MWCNTs are lower compared to other carbon electrode materials, which can be a disadvantage depending on the application. Therefore, several treatments have been proposed to increase the surface area of the MWCNTs, such as polymer deposition [9-11], electrode composite formation with transition metal oxides $[12,13]$ or physical/chemical activation [14-16]. Nevertheless, the single contribution of the electrical double layer to the specific capacitance of the MWCNTs (due to the absence of surface functionalities) makes them an ideal material to study the pseudocapacitive contribution of an electrochemical active compound. 
The main goal of this work is to establish an alternative route to increase the specific capacitance values of MWCNT-based EDLC. The effect of incorporating a faradaic contribution into the double-layer capacitance provided for the MWCNTs was evaluated by dissolving an electrochemically active compound, indigo carmine (IC) into the electrolyte. A cooperative effect can be expected when combining the electrical double layer formation with the development of a redox reaction. Thus, the total capacitance of the overall system will be the sum of the EDLC capacitance and the pseudocapacitance working in parallel $[17,18]$.

It has been reported that the redox activity of IC is not affected by the composition, the microscopic structure or the presence of defects in the carbon-based electrodes. Therefore, it does not exhibit great differences in charge transfer among different working electrodes [19]. For all this characteristics, IC was selected as electrochemically active compound in the present study.

\section{2.- EXPERIMENTAL}

\subsection{Materials}

MWCNTs supplied by Sigma-Aldrich were used as the electrode active material. The apparent surface area of the nanotubes, determined from the $\mathrm{N}_{2}$-adsorption isotherm using the BET equation, was $210 \mathrm{~m}^{2} / \mathrm{g}$ and the average pore size was $2 \mathrm{~nm}$.

Indigo carmine supplied by Sigma-Aldrich was utilized as the electrochemical active compound. IC is sensitive to light as well as to different oxidizing agents. Thereby, the working solutions $(0.05 \mathrm{M}$ in concentration) were freshly prepared with $1 \mathrm{M}$ $\mathrm{H}_{2} \mathrm{SO}_{4}$ as supporting electrolyte and kept in an opaque flask prior to the experiments. 


\subsection{Electrode preparation and electrochemical characterization}

Disc electrodes with a geometric surface area of $1.13 \mathrm{~cm}^{2}$ and containing $75 \mathrm{w} \%$ of MWCNTs and $25 \mathrm{w} \%$ of binder (polyvinylidene fluoride, PVDF) were prepared. All the electrodes were dried in a vacuum oven at $110^{\circ} \mathrm{C}$ overnight before each experiment.

Two electrode capacitors fitted with a glassy fibrous separator and gold current collectors in a Swagelok ${ }^{\circledR}$-type cell were employed. The tests were carried out using $1 \mathrm{M} \mathrm{H}_{2} \mathrm{SO}_{4}\left(\mathrm{H}_{2} \mathrm{SO}_{4}\right)$ and $0.05 \mathrm{M}$ indigo carmine dissolved in $1 \mathrm{M} \mathrm{H}_{2} \mathrm{SO}_{4}\left(\mathrm{IC}_{-}-\mathrm{H}_{2} \mathrm{SO}_{4}\right)$ as electrolytes. Measurements were performed in an operating voltage window of 0-1 V.

Electrochemical measurements were performed in a Biologic VMP multichannel potenciostate. Cyclic voltammetry $(\mathrm{CV})$, galvanostatic charge/discharge and impedance spectroscopy tests were carried out to assess the capacitance properties of the devices. Cyclic voltammetry experiments were performed at varying scan rates $\left(v: 1-50 \mathrm{mV} . \mathrm{s}^{-1}\right)$. Galvanostatic charge/discharge cycling was conducted with current densities ranging from 1-80 $\mathrm{mA} \mathrm{cm}^{-2}$. The specific capacitance (Ce) of the system was obtained applying the following equation: $C e(F / g)=2 I / m(d V / d t)$ to the constant current discharge curve (avoiding the ohmic drop), where $I$ is the current in Amperes, $\mathrm{dV} / \mathrm{dt}$ is the slope of the discharge curve and $m$ is the weight of the active material in the working electrode (the binder was not taken into account). The capacitance values were expressed in Farads (F) per mass of active material present in the lightest electrode. The impedance spectroscopy test was carried out from $100 \mathrm{KHz}$ to $1 \mathrm{mHz}$. The electrochemical behaviour of the electrode/electrolyte system was also studied by a three-electrode configuration and by synchronous experiments in two and three electrodes in a "T-type Swagelok ${ }^{\circledR}$ cell. In this configuration a two-electrode cell is assembled and at the third 
end connection a reference electrode is incorporated. This configuration allows the potential at which the anode and cathode are operating to be determined, as these can be monitored throughout the two-electrode experiments. A platinum mesh was used as counter electrode in the three-electrode configuration. The reference electrode used was $\mathrm{Hg} / \mathrm{Hg}_{2} \mathrm{SO}_{4}$.

All measurements were performed at $298 \mathrm{~K}$. Long-term cycling experiments were conducted at a voltage window of $1 \mathrm{~V}$ and a current density of $8.8 \mathrm{~mA} \cdot \mathrm{cm}^{-2}$ (360 $\left.\mathrm{mA} \cdot \mathrm{g}^{-1}\right)$.

\section{3.- RESULTS AND DISCUSSION}

Fig. 1(a) shows an example of the charge-discharge curves obtained for the MWCNT-based EDLC employing $1 \mathrm{M} \mathrm{H}_{2} \mathrm{SO}_{4}$ and $0.05 \mathrm{M}$ IC- $\mathrm{H}_{2} \mathrm{SO}_{4}$ as electrolytes, which were used to calculate the specific capacitance. Fig. 1(b) shows the influence of the current density on the specific capacitance values obtained for the MWCNTs and for the system with the redox electrolyte. MWCNTs show an ideal triangular shape for the charge-discharge cycles in $\mathrm{H}_{2} \mathrm{SO}_{4}$, which is characteristic of a purely electrostatic capacitor where only the double-layer contributes to the total capacitance. As can be expected from the area of the charge-discharge cycles, MWCNTs display a low specific capacitance in all the current density range studied. However, when IC is incorporated to the supporting electrolyte, the capacitance values significantly increase. In fact, these values are at least two times higher after the addition of the IC, and at low current densities this increase was even greater: from $\sim 17$ to $50 \mathrm{Fg}^{-1}$. This leads to an increase of the energy density from 0.6 to $1.7 \mathrm{Wh} \mathrm{kg}^{-1}$. Moreover, the conductivity is not result significantly modified by the addition of the redox compound, as can be seen in Fig. 
1(c) where the high frequency region of the impedance spectrum is plotted. This is consistent with the similar ohmnic drop value calculated from the charge-discharge tests in the two electrolytes $\left(0.4 \Omega \mathrm{cm}^{-2}\right)$. Therefore, the power density is not significantly affected in the new system.

From these results it can be concluded that the increase in capacitance observed with the use of the redox electrolyte is due to the additional capacitive contribution of the faradaic reactions by the IC, as the shape of the charge-discharge cycles and the voltammograms show (Fig. 1 (a) and (d)). The cyclic voltammograms obtained in the two-electrode cell with IC- $\mathrm{H}_{2} \mathrm{SO}_{4}$ as electrolyte display well-defined redox humps, meanwhile the voltammograms obtained for the MWCNTs in $\mathrm{H}_{2} \mathrm{SO}_{4}$ show a ideal rectangular shape characteristic of an electrical double layer capacitor. In addition, the charge-discharge cycles present plateaus characteristic of redox reactions that occur at a constant potential after the incorporation of IC to the cell. It should also be pointed out that the IC-containing supercapacitor shows a higher dependence on the current density applied, particularly below $20 \mathrm{~mA} \mathrm{~cm}^{-2}$. This suggests that the two energy storage processes (double layer formation and pseudocapacitive phenomena) have different kinetic dependences.

In order to clarify the behaviour of each electrode in this system, a study using a T-type Swagelok cell and a three-electrode configuration was carried out. Fig. 2 shows a charge-discharge cycle obtained in $\mathrm{IC}^{-} \mathrm{H}_{2} \mathrm{SO}_{4}$ in a two-electrode configuration (cell voltage from 0 to $1 \mathrm{~V}$, left $\mathrm{Y}$-axis) and the voltage profile where anode and cathode are operating (right Y-axis). When the cell is in the discharged state $(0 \mathrm{~V}$, left Y-axis in Fig. 2) the anode and cathode are at the same potential $\left(-0.36 \mathrm{~V}\right.$ vs. $\left.\mathrm{Hg} / \mathrm{Hg}_{2} \mathrm{SO}_{4}\right)$. When the supercapacitor is in the completely charged state $(1 \mathrm{~V})$, the positive electrode has reached $0.25 \mathrm{~V}$ vs. $\mathrm{Hg} / \mathrm{Hg}_{2} \mathrm{SO}_{4}$, whereas the negative electrode has decreased to $-0.73 \mathrm{~V}$ 
vs. $\mathrm{Hg} / \mathrm{Hg}_{2} \mathrm{SO}_{4}$. Thus, the positive and negative electrodes are working in a range of potential of 0.61 and $0.37 \mathrm{~V}$, respectively, reflecting a different performance of the anode and cathode. The operating voltage of the cell ranges from -0.73 to $0.25 \mathrm{~V}$ vs. $\mathrm{Hg} / \mathrm{Hg}_{2} \mathrm{SO}_{4}$. Figure 3(a) displays a representative cyclic voltammograms obtained in a three-electrode configuration for the MWCNTs-based capacitor, before and after the addition of IC, when a potential scan ranging from -0.7 to +0.25 (vs. $\mathrm{Hg} / \mathrm{Hg}_{2} \mathrm{SO}_{4}$ as reference electrode) was applied. Once again, a perfectly rectangular voltammogram can be observed in the first case, while the $\mathrm{CV}$ response in the $\mathrm{IC}-\mathrm{H}_{2} \mathrm{SO}_{4}$ electrolyte clearly shows capacitive peaks that are indicative of redox reactions. These faradaic processes occur in the anodic and cathodic scans, which means that pseudocapacitance is readily used in the symmetric supercapacitor. This voltammetric profile is characterized by a well-defined pair of faradaic peaks at $E_{p, a}=-0.34 \mathrm{~V}$ and $E_{p, c}=-0.43 \mathrm{~V}$ (vs. $\mathrm{Hg} / \mathrm{Hg}_{2} \mathrm{SO}_{4}$ ) (process I) and a more positive anodic peak at $\mathrm{E}_{\mathrm{p}, \mathrm{a}}=0.25 \mathrm{~V}$ (vs. $\mathrm{Hg} / \mathrm{Hg}_{2} \mathrm{SO}_{4}$ ) (process II). As described elsewhere [20] both are two-electron processes (in the presence of protons) attributed to the oxidation/reduction of leucoindigoid specie/indigo carmine and the oxidation of indigo carmine/dehydroindigoid species, respectively. In our study, the difference between from the anodic peak potential $\mathrm{E}_{\mathrm{p} \text {, a }}$ and the cathodic peak potential $\left(\mathrm{E}_{\mathrm{p}}\right)_{\mathrm{c}}$, defined as $\Delta \mathrm{E}_{\mathrm{p}}=\mathrm{E}_{\mathrm{p}, \mathrm{a}}-\mathrm{E}_{\mathrm{p}, \mathrm{c}}$, is $0.09 \mathrm{~V}$ for the process I, which is greater than the expected Nerstian value for a two-electron process $(0.029 \mathrm{~V})$. This behaviour found in our system can be explained by the fact that this redox compound can be sensitive to the composition or to the microscopic structure of the carbon-based electrodes [21]. This affects the redox activity of this molecule, leading to a decrease in electron transfer reactivity.

In order to understand the nature of this electrodic process, cyclic voltammograms were recorded in $\mathrm{IC}_{-} \mathrm{H}_{2} \mathrm{SO}_{4}$ at various scan rates (from $1 \mathrm{mV} / \mathrm{s}$ to 20 
$\mathrm{mV} / \mathrm{s})$ (Fig. $3 \mathrm{~b}$ ). A linear relationship between the peak current and the square root of the scan rate was found, for both the anodic and cathodic currents, so that the oxidation and reduction of the indigo carmine are diffusion-controlled processes (Figure 4). The corresponding linear equations are:

$$
\begin{array}{lll}
\text { Anodic process: } & \mathrm{I}_{\mathrm{pa}}(\mathrm{A})=0.23 \mathrm{v}^{1 / 2}-0.003 & \mathrm{r}=0.999 \\
\text { Cathodic process: } & \mathrm{I}_{\mathrm{pc}}(\mathrm{A})=-0.19 \mathrm{v}^{1 / 2}+0.009 & \mathrm{r}=0.997 \\
& v=0.001-0.05 \mathrm{~V} . \mathrm{s}^{-1}
\end{array}
$$

Moreover, from Fig. 3 (b), it was found that the influence of the scan rate mainly had two effects, (1) the increase of the redox peak currents and (2) the increase in the peak potential separation (from $0.08 \mathrm{~V}$ to $0.35 \mathrm{~V}$ ) when $v$ is increased. These behaviours confirm that both processes are diffusion controlled.

The formal potential of electrode $\mathrm{E}^{0}$ for process $\mathrm{I}$ was estimated from the voltammograms by taking the mean of the average of the anodic and cathodic peak potentials, $E_{p, a}$ and $E_{p, c}$ and applying the following equation: $E^{0}=\frac{\Sigma\left(E p_{a}+E p_{c}\right) / 2}{m}$, where $\mathrm{m}$ is the total number of scans. The formal potential of the redox couple was found to be $0.393 \mathrm{~V}$.

The mechanism of the electrodic process of IC (Fig. 5) can be inferred from a study of the electrochemical reduction of this molecule carried out by Bond et al. [20]. The first electrodic process (I) involves the oxidation of the conjugated enol groups of the leuco-indigo species giving rise to the diketone structure of the indigo carmine. This is reduced to the starting molecule in the reverse scan. The second electrodic process (II) involves the oxidation of indigo through the $-\mathrm{NH}$ groups of the indol structures to yield dehydro-indigo (III). 
In order to evaluate the suitability of the system over long periods of time, extended charge-discharge cycles were carried out with another cell. Figure 6(a) shows a reduction in the specific capacitance values of only $30 \%$ after 10,000 cycles at $360 \mathrm{~mA} \mathrm{~cm}{ }^{-2}$, occurring the most drastic fall within the first 5,000 cycles, after which the values remain stable. The efficiency of the cells was close to $100 \%$ during the 10,000 cycles, as can be seen in Figure 6(b). The initial loss of capacitance can be attributed to the decrease on the redox activity of the redox process II. As can be seen in Figure 6(c), this redox couple tends to disappear after several cycles (around 2,000 cycles), whereas the peaks associated to the process I remain unmodified. Accordingly, the charge-discharge cycles showed a significant change in shape in the voltage close to $0 \mathrm{~V}$ (Figure 6(d)). In conclusion, from a practical point of view, it is worth highlighting the high reversibility achieved with this innovative redox electrolyte.

\section{4.- CONCLUSIONS}

The specific capacitance of a MWCNT-based EDLC was improved by the addition of an electrochemically active compound (IC) to the supporting electrolyte $\left(\mathrm{H}_{2} \mathrm{SO}_{4}\right)$. At low current densities the capacitance values increased from $\sim 20 \mathrm{Fg}^{-1}$ (corresponding to the electrical formation of the double layer) to $50 \mathrm{Fg}^{-1}$, which corroborates the pseudocapacitive contribution of the redox reaction. The good resistance obtained for the MWCNT-based capacitor was not significantly modified after the addition of IC to the supporting electrolyte. The long-term cycling behavior of the device was quite good, with a reduction in the capacitance values of $30 \%$ after 10,000 cycles and an efficiency of nearly $100 \%$ during the cycling. As the MWCNTs employed as electrode material have high chemical and mechanical stability, the 
capacitance reduction observed can be attributed to a decrease in the redox activity of the electrodic process II of the indigo carmine.

Thus a new highly promising way to increase electric energy storage is provided by this hybrid system that combines two energy storage processes: the double layer formation characteristics of EDLCs and the faradaic reactions characteristic of batteries.

\section{Acknowledgements.-}

This work was supported by the MICINN (Project MAT2007-61467). Silvia Roldán thanks MICINN for a FPI predoctoral grant.

\section{REFERENCES}

[1] C Niu, E. K. Sichel, R. Hoch, D. Moy, H. Tennet, Appl. Phys. Lett. 70 (1997) 1480.

[2] E. Frackowiak, K. Méténier, V. Bertagna, F. Béguin, Appl. Phys. Lett. 77 (2000) 2421.

[3] R. Z. Ma, J. Liang, B. Q. Wei, B. Zhang, C. L. Xu, D. H. Wu, J. Power Sources 84 (1999) 126

[4] K. Hyeok, W. Seok, Y. Soo, Y. Chul, S. Mi, D. Chul, D. Jae, S. Chu, Y. Hee, Adv. Mat. 13 (2001) 497.

[5] B. Zhang, J. Liang, C. L. Xu, B. Q. Wei, D. B. Ruan, D. H. Wu, Mater. Lett. 51 (2001) 539

[6] J. H. Chen, W. Z. Li, D. Z. Wang, S. X. Yang, J. G. Wen, Z. F. Ren, Carbon 40 ( 2002) 1193.

[7] E. Frackowiak, F. Béguin, Carbon 40 (2002) 1775. 
[8] K. Jurewick, K. Babel, R. Pietrzak, S. Delpeux, H. Wachowska, Carbon 44 (2006) 2368.

[9] Q. Xiao, X. Zhou, Electrochimica Acta 48 (2003) 48:575.

[10] E. Frackowiak, K. Jurewica, S. Delpeux, F. Béguin, J. Power Sources 97 (2001) 822.

[11] S. Ben-Valid, B. Botka, K. Kamarás, A. Zeng, S. Yitzchaik, Carbon, In Press, Available online 9 April 2010.

[12] E. Raimundo-Pinero, V. Khomenko, E. Frackowiak, F. Béguin, J. Electrochem. Soc. 152 (2005) A229.

[13] G. H. Deng, X. Xiao, J. H. Chen, X. B. Zeng, D. L. He, Y. F. Kuang, Carbon 43 (2005) 1566.

[14] Q. Jiang, M. Z. Qu, G. M. Zhou, B. L. Zhang, Z. L. Yu, Mater. Lett. 57 (2002) 988.

[15] R. Z. Ma, J. Liang, B. Q. Wie, B. Zhang, C. L. Xu, D. H. Wu, J. Power Sources 84 (1999) 126.

[16] C. M. Liu, H. B. Cao, Y. P. Li, H. B. Xu, Y. Zhang, Carbon 44 (2006) 2919.

[17] K. W. Leitner, B. Gollars, M. Winter, J. O. Besenhard, Electrochimica Acta 50 (2004) 199.

[18] S. Sarangapani, B. V. Tilak, C. P. Chen, J. Electrochem. Soc. 143 (1996) 3791.

[19] P. Fanjul-Bolado, D. Hernández-Santos, P. J. Lamas-Ardisana, A. Martín-Pernía, A. Costa García, Electrochimica Acta 53 (2008) 3635.

[20] A. M. Bond, F. Marken, E. Hill, R. G. Compton, H. Hügel, J. Chem. Soc. Perkin Trans. 2 (1997) 1735. 


\section{FIGURES}

Figure 1. (a) Charge and discharge profiles at $1 \mathrm{~mA}\left(0.88 \mathrm{~mA} \cdot \mathrm{cm}^{-2}, 41 \mathrm{~mA} \cdot \mathrm{g}^{-1}\right),(\mathrm{b})$ variation of specific discharge capacitance values with current density, (c) high frequency region of the Nyquist plot, and (d) cyclic voltammogram at $50 \mathrm{mV} \cdot \mathrm{s}^{-1}$ for IC$\mathrm{H}_{2} \mathrm{SO}_{4}$ and $\mathrm{H}_{2} \mathrm{SO}_{4}$. Two-electrode configuration. (a.u.: arbitrary units)

Figure 2. Galvanostatic cycle for MWCNTs-based electrode (left Y-axis) and the working potentials of the positive and negative electrodes (right $\mathrm{Y}$-axis) in $\mathrm{IC}-\mathrm{H}_{2} \mathrm{SO}_{4}$. Current density $8.8 \mathrm{~mA} / \mathrm{cm}^{2}$ (current load $340 \mathrm{~mA} / \mathrm{g}$ ).

Figure 3. Cyclic voltammograms for $\mathrm{IC}-\mathrm{H}_{2} \mathrm{SO}_{4}$ and $\mathrm{H}_{2} \mathrm{SO}_{4}$ in a three electrode configuration at: (a) $1 \mathrm{mV} / \mathrm{s}$, (b) various scan rates (from $1 \mathrm{mV} / \mathrm{s}$ to $20 \mathrm{mV} / \mathrm{s}$ ). $E_{i}=E_{f}=-$ $0.7 \mathrm{~V}, \mathrm{E}_{\lambda}=0.25 \mathrm{~V}$.

Figure 4. Dependence of the cathodic and anodic peak currents on the scan rate. Electrolyte: $\mathrm{IC}-\mathrm{H}_{2} \mathrm{SO}_{4}$

Figure 5. Schematic electrodic processes of indigo carmine.

Figure 6. Variation in the (a) specific capacitance values, (b) efficiency, (c) voltammetric response $\left(1 \mathrm{mV} . \mathrm{s}^{-1}\right)$ and (d) galvanostatic charge-discharge profile $\left(8.84 \mathrm{~mA} \cdot \mathrm{cm}^{-2}\right)$ with the number of cycles. Electrolyte: $\mathrm{IC}-\mathrm{H}_{2} \mathrm{SO}_{4}$ 
Figure 1. (a) Charge and discharge profiles at $1 \mathrm{~mA}\left(0.88 \mathrm{~mA} \cdot \mathrm{cm}^{-2}, 41 \mathrm{~mA} \cdot \mathrm{g}^{-1}\right)$, (b) variation of specific discharge capacitance values with current density, (c) high frequency region of the Nyquist plot, and (d) cyclic voltammogram at $50 \mathrm{mV} \cdot \mathrm{s}^{-1}$ for IC$\mathrm{H}_{2} \mathrm{SO}_{4}$ and $\mathrm{H}_{2} \mathrm{SO}_{4}$. Two-electrode configuration. (a.u.: arbitrary units)

a)

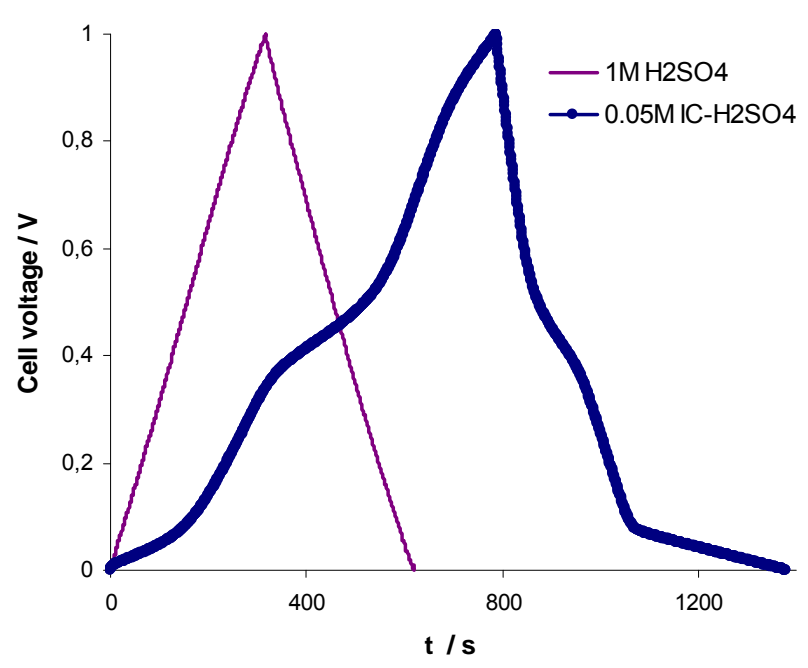

c)

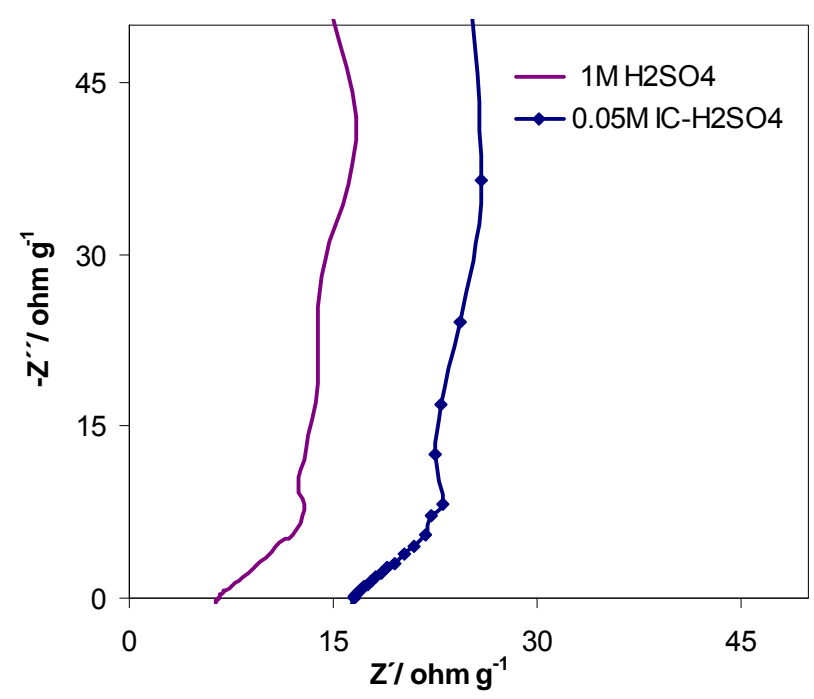

b)

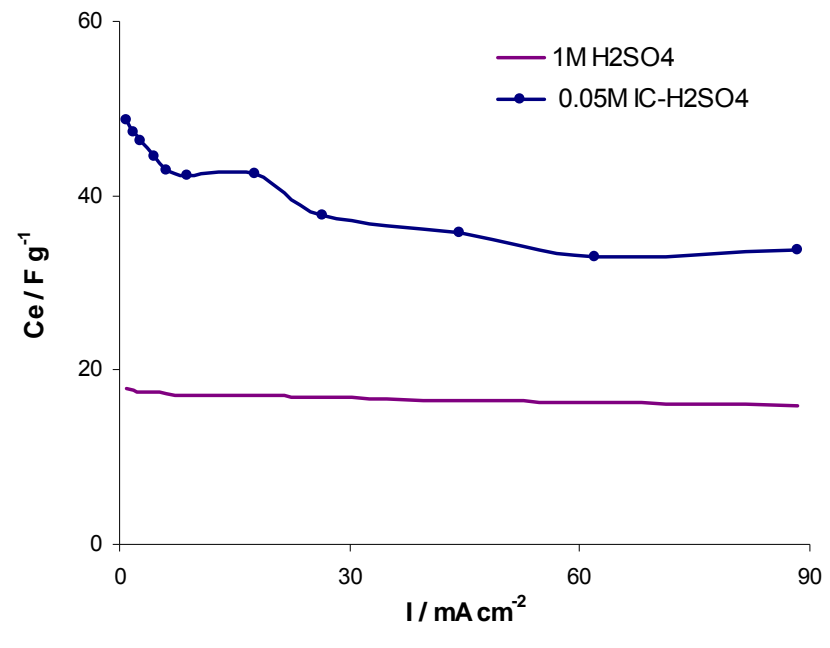

d)

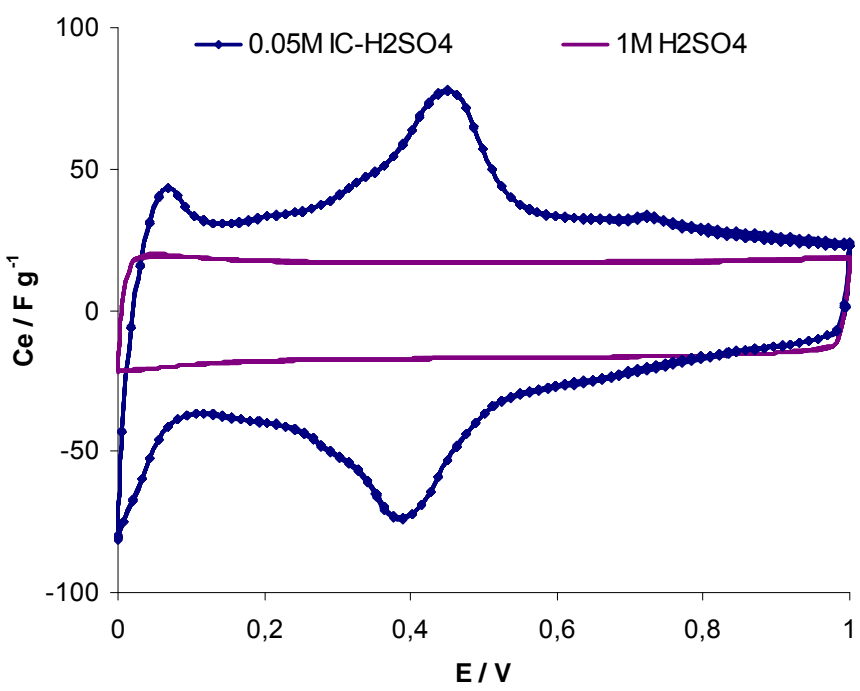


Figure 2. Galvanostatic cycle for MWCNTs-based electrode (left Y-axis) and the working potentials of the positive and negative electrodes (right $\mathrm{Y}$-axis) in $\mathrm{IC}-\mathrm{H}_{2} \mathrm{SO}_{4}$. Current density $8.8 \mathrm{~mA} / \mathrm{cm}^{2}$ (current load $340 \mathrm{~mA} / \mathrm{g}$ ).

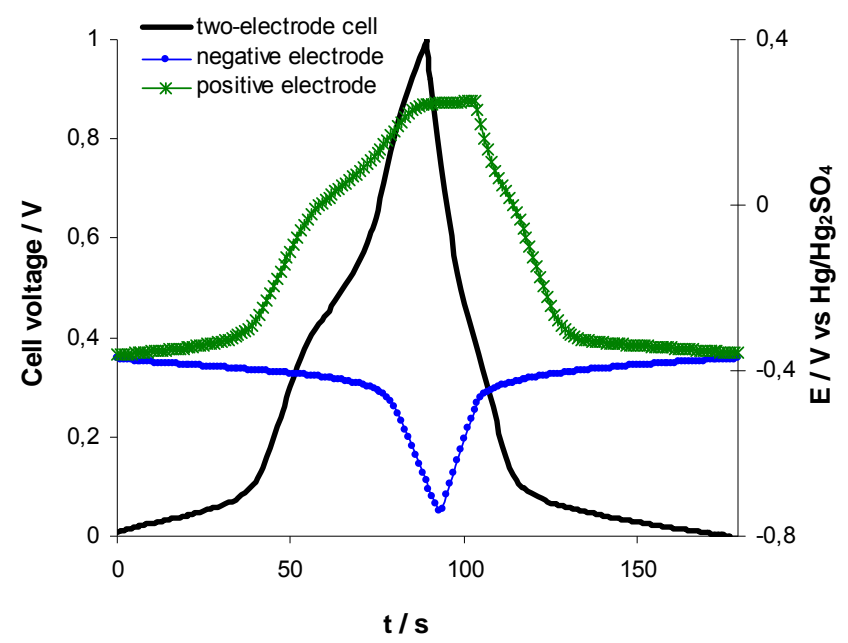


Figure 3. Cyclic voltammograms for $\mathrm{IC}-\mathrm{H}_{2} \mathrm{SO}_{4}$ and $\mathrm{H}_{2} \mathrm{SO}_{4}$ in a three- electrode configuration at: (a) $1 \mathrm{mV} / \mathrm{s}$, (b) various scan rates (from $1 \mathrm{mV} / \mathrm{s}$ to $20 \mathrm{mV} / \mathrm{s}$ ) $E_{i}=E_{f}=$ $0.7 \mathrm{~V}, \mathrm{E}_{\lambda}=0.25 \mathrm{~V}$

a)

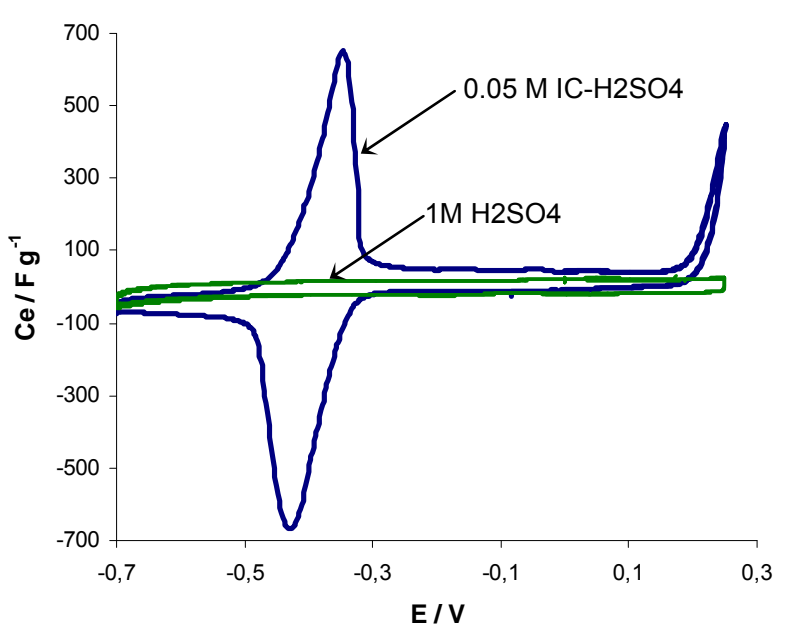

b)

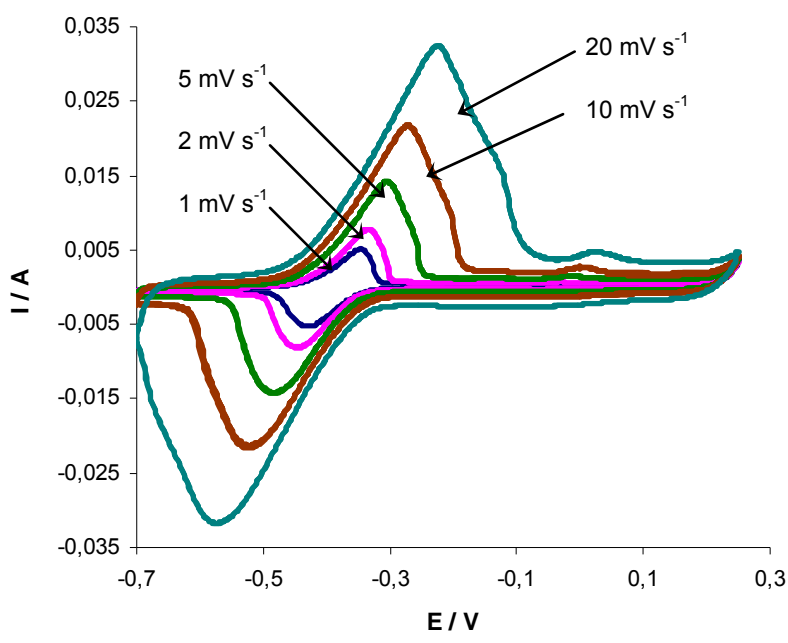


Figure 4. Dependence of the cathodic and anodic peak currents on the scan rate.

Electrolyte: IC- $\mathrm{H}_{2} \mathrm{SO}_{4}$

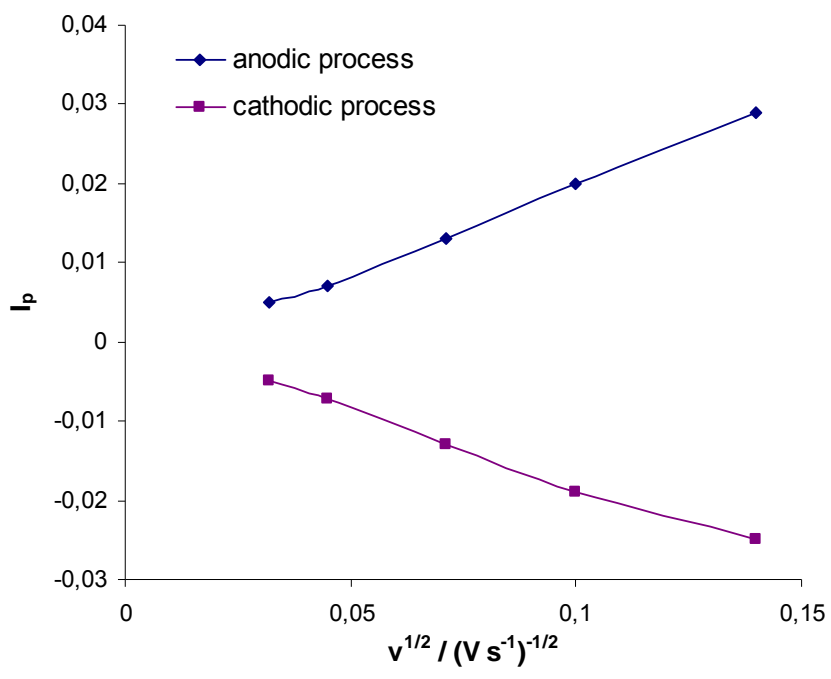


Figure 5. Schematic electrodic processes of indigo carmine.
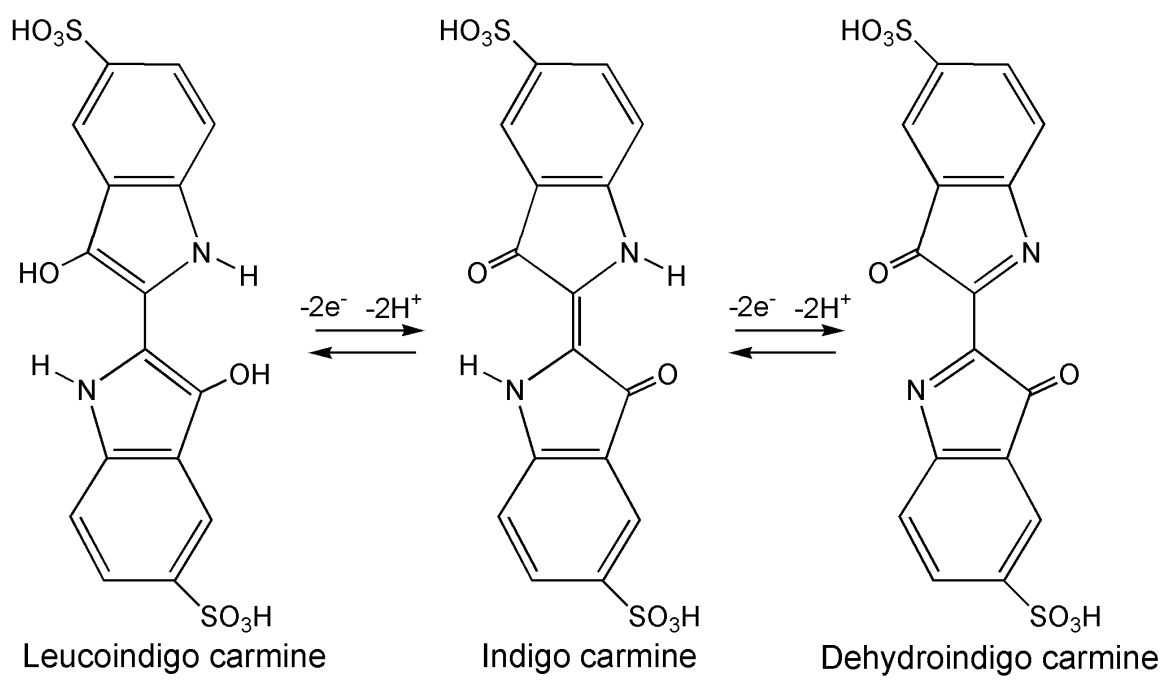
Figure 6. Variation in the (a) specific capacitance values, (b) efficiency, (c) voltammetric response $\left(1 \mathrm{mV} . \mathrm{s}^{-1}\right)$ and (d) galvanostatic charge-discharge profile $\left(8.84 \mathrm{~mA} . \mathrm{cm}^{-2}\right)$ with the number of cycles. Electrolyte: $\mathrm{IC}-\mathrm{H}_{2} \mathrm{SO}_{4}$

a)

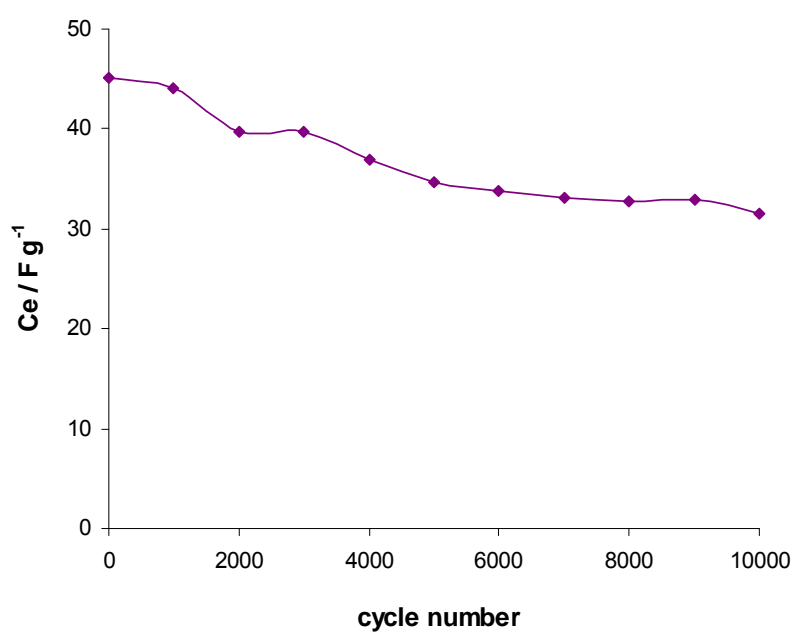

c)

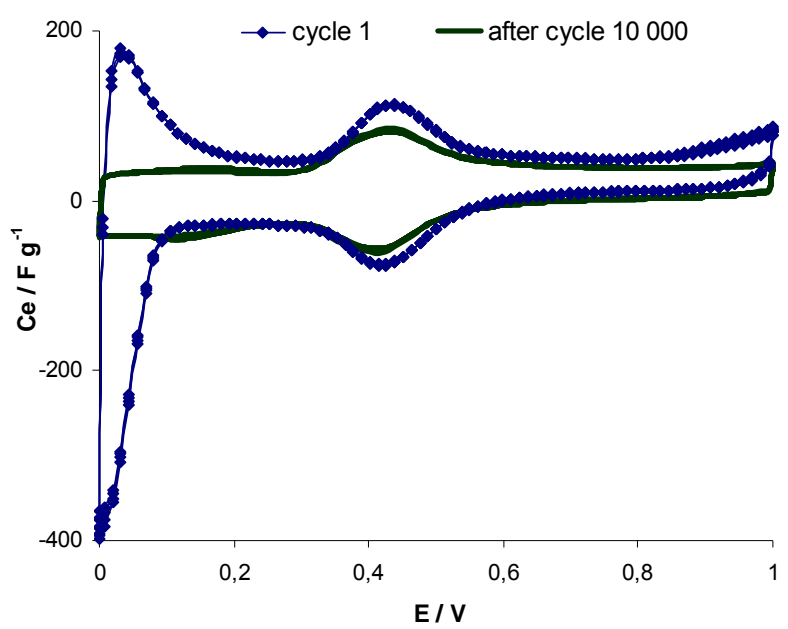

b)

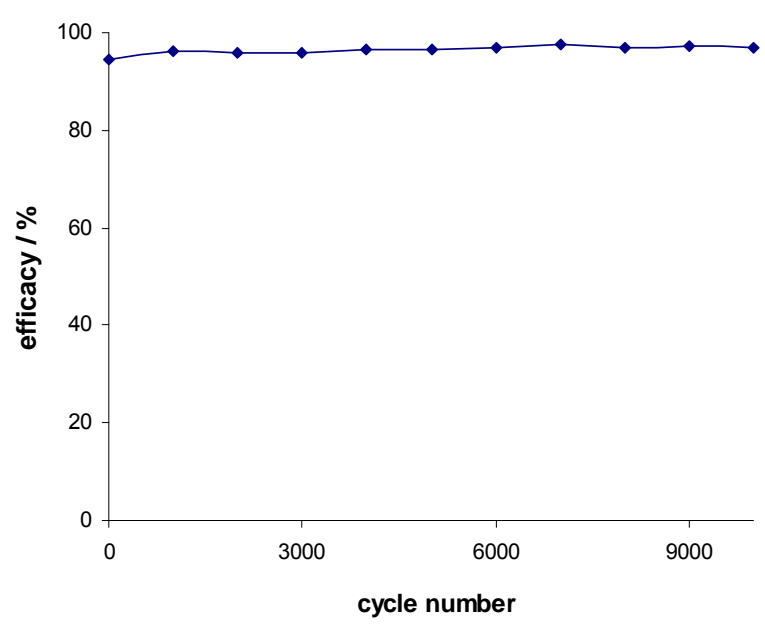

d)

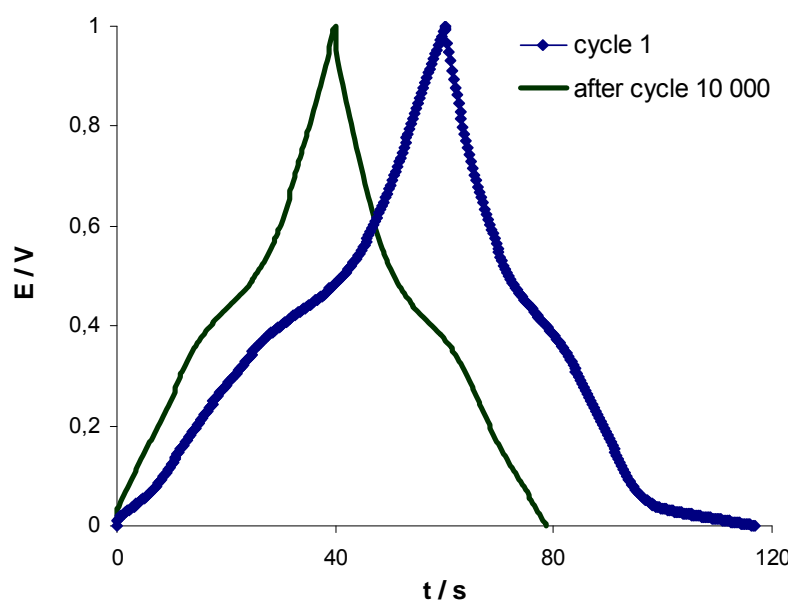


